\title{
PAREDES Y PUENTES: debates en torno de la acción social
}

\author{
Javier Arzuaga Magnoni \\ Centro de Investigación y Estudios Avanzados en Ciencias Politicas y Administración \\ Pública, UAEM
}

\section{PRESENTACIÓN}

La cuestión en torno de la acción social se encuentra definida por dos de los campos más problemáticos de las Ciencias Sociales: una que podríamos llamar la "teoría del sujeto" y la otra, la "teoría de la acción" propiamente dicha. La primera de ellas intenta responder a la pregunta ¿quiénes son los sujetos sociales? la segunda ¿cuáles son las pautas de comportamiento de esos sujetos sociales que se han definido?

La alta problematicidad que engendran estas preguntas es en sí misma la causa de que no tengan una respuesta única y definitiva en las Ciencias Sociales. Aunque el acuerdo es más esporádico que común en este ámbito, las preguntas que se realizan en relación con el sujeto y la acción social constituyen un campo aún más arduo en la medida en que son constitutivas de cualquier teoría social.

En una primera aproximación, podríamos definir la problemática planteada en los siguientes términos: ante la primera pregunta hay quienes sostienen que son los individuos los sujetos sociales por antonomasia; otros autores afirman que aunque son los individuos los sujetos sociales básicos, éstos en su acción crean instituciones que tienden a separarse de ellos, y que a partir de su autonomía se imponen sobre los individuos determinando su acción; mientras que un último conjunto asegura que si bien existen individuos en términos de corporalidades separadas, no existe en ellos nada que remita a la individualidad y que, por lo tanto, son las estructuras y las relaciones sociales que se establecen con independencia de la voluntad de los individuos los que prefiguran y determinan su acción, siendo estas estructuras los verdaderos sujetos socia- les. Llamaremos, para simplificar, a los primeros "individualistas", al segundo grupo "teorías intermedias" y al tercero grupo "estructuralistas". 
La respuesta a la segunda pregunta si bien está determinada por la primera, vuelve a dividir las aguas. Entre los "individualistas" se encuentran tanto quienes sostienen que la acción social es una acción racional y egoísta que se despliega en tomo de los procesos de intercambio; como quienes afirman que si bien la acción de los individuos es, en principio, racional y egoísta, existen situaciones en las que las pautas de la acción no son la racionalidad ni el egoísmo y que, por lo tanto, hay que ampliar el ámbito de las motivaciones de la acción. Entre las "teorías intermedias" encontraremos tanto a los que hacen hincapié en instituciones normativas como la ley; como a otros que propondrían un conjunto de instituciones más bastas como la organización del trabajo. Por último, entre los "estructuralistas" podríamos destacar a quienes sostienen que son las estructuras económicas las básicas para entender el comportamiento social y a otros que ponen el énfasis en estructuras psicológicas, etc.

Si bien esta descripción es parcial, engloba buena parte de las posturas en torno de la problemática planteada. Es evidente que no daremos respuesta aquí a lo que las Ciencias Sociales no resolvieron en toda su historia. El objeto de este trabajo es pues abordar la complejidad de las distintas propuestas y tratar de establecer los aportes y las controversias que surgen entre ellas.

\section{LAS TEORIAS ESTRUCTURALISTAS}

Por "teorías estructuralistas" no entendemos ni una escuela particular dentro del pensamiento social, ni una cuestión peyorativa, sólo hacemos referencia a aquellas propuestas que hacen hincapié en la preeminencia de las estructuras sociales por sobre los individuos como determinantes del proceso social.

En términos generales, estas propuestas sostienen la existencia de elementos supraindividuales que prefiguran la acción de los individuos y que la configuración de estos elementos responde a procesos históricos particulares en los que la voluntad individual no interviene como tal. Antes bien, por fuera de los individuos, y en la medida en que éstos se encuentran definidos por relaciones, se despliegan lógicas que los envuelven y que tienen su propia dinámica y racionalidad.

Aunque el campo de las teorías estructuralistas de la acción social es muy amplio, ${ }^{1}$ destacaremos, por razones de espacio y en virtud de su importancia, sólo una: la de Karl Marx.

1 Recordemos que podrían ser englobadas bajo este rótulo las teorías funcionalistas desde Talcott Parsons hasta Niklas Luhmann, así como todas las tendencias derivadas del marxismo, desde el estructuralismo francés hasta la Escuela de Frankfurt, y autores como Emile Durkheim, Norbert Elías entre otros. 


\section{II.1.Relaciones de producción y clases sociales en Marx}

El punto de partida de la interpretación de Marx supone que los individuos, en su acción, se encuentran determinados por las relaciones de producción. $\mathrm{Al}$ respecto, en El capital, Marx afirma que:

"las máscaras que en lo económico asumen las personas, no son más que personificaciones de las relaciones económicas como portadoras de las cuales dichas personas se enfrentan mutuamente.".

Para sostener esta determinación, es necesario considerar el proceso de liberalización del individuo. Marx sostiene que en el capitalismo el obrero se presenta como libre vendedor de fuerza de trabajo. Este proceso se vincula con la forma particular que asume la explotación en ese modo de producción, y lleva a relacionar a los individuos entre sí como propietarios de mercancías, "cuya voluntad reside en dichos objetos".

Dado que el capitalista posee capital y el obrero su fuerza de trabajo, sus respectivas acciones estarán determinadas por el hecho de ser poseedores de capital y de fuerza de trabajo. Las relaciones de producción, ajenas a la voluntad de los individuos, se imponen sobre su voluntad. Por lo que la acción individual pierde su carácter de acción guiada por presupuestos propios de cada persona para estar subordinadas a las relaciones sociales de producción.

La acción individual, como tal, no existe. Son las relaciones de producción las que se manifiestan en la acción de cada individuo. Su condición de propietarios de capital y de fuerza de trabajo, de explotadores y explotados, los vincula de manera particular con los objetos y entre sí.

Ahora bien, ¿el hecho de que la acción individual no exista como tal hace que debamos considerar' que toda acción es una acción colectiva de clase? La respuesta que Marx nos brinda parece decimos que no, dado que

"los diferentes individuos sólo forman una clase en cuanto se ven obligados a sostener una lucha común contra otra clase, pues por lo demás ellos mismos se enfrentan unos con otros, hostilmente, en el plano de la competencia".

Las relaciones de producción conducen al propietario de los medios de producción a comportarse como capitalista, y al propietario de la fuerza de trabajo a comportarse como obrero, sin que ello los lleve inmediatamente a la acción colectiva. La acción colectiva, la acción de clase, si bien está

\footnotetext{
2 en Marx, K.: El Capital, p. 104

3 en El Capital... op. cit. p. 103

4 en Marx, K. y Engels, F.: La Ideologia Alemana, p. 60-61.
} 
determinada por la posición de los individuos frente a los medios de producción, se encuentra mediatizada por el reconocimiento de la identidad de los intereses de clase, la toma de conciencia y la organización.

Sin embargo, el paso a la conciencia y organización y organización de clase no se logra en un terreno político independiente de otro económico, sino que está contenido en el proceso de producción mismo. Marx afirma que

"la división del trabajo lleva aparejada, además, la contradicción entre el interés del individuo concreto o de una determinada familia y el interés común de todos los individuos relacionados entre sí interés común que no existe, ciertamente, tan sólo en la idea, como algo «genera!», sino que se presenta en la realidad; ante todo, como una relación de mutua dependencia de los individuos entre los que aparece dividido el trabajo». ${ }^{5}$

Consecuentemente,

"Para que la clase oprimida pueda liberarse, es preciso que las fuerzas productivas ya adquiridas y las relaciones sociales vigentes no puedan seguir existiendo unas aliado de otras. De todos los instrumentos de la producción, la fuerza productiva más grande es la propia clase revolucionaria. La organización de los elementos revolucionarios como clase supone la existencia de todas las fuerzas productivas que podian engendrarse en el seno de la vieja sociedad". 6

Las relaciones de producción y la división del trabajo, que traen aparejada, conducen, en el capitalismo, a una experiencia contradictoria de los individuos. Por un lado, como experiencias atomizadas por la competencia, lo cual no implica la existencia de individuos. Por otro lado, la experiencia de clase producto de la explotación, que no se manifiesta de forma inmediata.

Así el paso a la acción colectiva de clase implica el reconocimiento y la desarticulación de la contradicción. Es una experiencia consciente, contra la cual opera el aparato institucional del modo de producción capitalista.

\section{LAS TEORIAS INDIVIDUALISTAS}

Una primera aproximación individualista a la teoría de la acción es la que se ha dado en llamar "individualismo metodológico". Esta aproximación parte del supuesto

"de que todos los fenómenos sociales (su estructura y su cambio) son explicables, en principio, de forma que solamente impliquen individuos (sus propiedades, sus objetivos, sus creencias y sus acciones)"?

5 en La ideologia... op. cit. p. 34.

6 en Marx, K.: La miseria de la filosofia, p. 159.

7 En Elster, J.: "Making sense o, Marx", p. 5. 
A pesar de compartir este supuesto, el individualismo metodológico ha sido residencia de propuestas provenientes de tradiciones tan diferentes como el neoliberalismo y el marxismo.

En su matriz neoliberal, el individualismo metodológico se ha manifestado radicalmente en contra del marxismo y de todas las propuestas que, en general, consideran la existencia de lógicas, instituciones o estructuras supraindividuales. En esta versión, que llamaremos radical, los fenómenos sociales sólo encuentran explicación en la acción de individuos racionales y egoístas y en el intercambio entre ellos.

En su versión marxista, la corriente que se ha autodenominado "marxismo analítico" incorpora elementos tales como la solidaridad, la existencia y pertinencia de entidades supraindividuales, y en la existencia de características individuales de relación, denostadas por los individualistas radicales.

Precediendo a éstas, podríamos encontrar una segunda aproximación individualista: la de Max Weber. ${ }^{8}$ La diferencia fundamental del subjetivismo de Weber con el individualismo metodológico radicaría en el hecho de que los fundamentos de la acción son más amplios que los de la acción racional.

\section{III.1. Acción racional y egoismo en el pensamiento neoliberal}

El punto de partida de la perspectiva neo liberal para explicar la acción individual es, como se dijo, la consideración del individuo como un sujeto egoísta, racional y maximizador de beneficios. Los individuos egoístas se benefician mutuamente a través del intercambio, estos buscan, a partir de ese proceso, alcanzar su máxima satisfacción colectiva, de modo tal que, como afirma Hayek,

"el mercado es el único mecanismo descubierto capaz de facilitar a los diferentes actores la información que les permite valorar las relativas ventajas de la alternativa utilización de aquellos recursos cuya existencia y especificas caracteristicas tienen conocimiento directo y cuyo adecuado empleo redunda en beneficio de un amplio conjunto de sujetos asilados $y$ desconocidos".

El intercambio a través del mercado, como proceso natural y conquista evolutiva, induce a la acción individual de los sujetos egoístas lo cual les garantiza un bienestar máximo comparado con el que podría alcanzarse colectivamente si trataran de intervenir en forma voluntaria en la definición de la naturaleza del intercambio, modificando su carácter espontáneo.

8 Es evidente que la teoría weberiana es anterior al individualismo metodológico. La tratamos después sólo por motivos que atañen a la exposición.

9 en Hayek, F.A.: La fatal arrogancia: los errores del socialismo, p. 133. 
Para que el proceso de intercambio pueda inducir esas prácticas individuales, los sujetos cuentan, por un lado, con la libre disposición de sus bienes -de no ser así, se interrumpiría el despliegue espontáneo del orden social comandado por el mercado e induciría a los individuos a prácticas maximizadoras en las que se sacrificaría a algunos de ellos en favor de otros, ${ }^{10} \mathrm{y}$, por el otro, con la información suficiente para la toma fe decisiones articulada en tomo al sistema de precios.

Así, la acción individual supone un acto racional en el cual individuos egoístas actúan con arreglo a su máximo bienestar y utilizan la información disponible en el mercado para estructurar, por un lado, aquello que habrán de entender por bienestar (es decir, su conjunto de preferencias en un marco de escasez), y, por el otro, los medios y las decisiones para alcanzarlo.

Por otra parte, los individuos encontrarán un inconveniente adicional en la consecución de sus fines. Además de obtener la libertad necesaria para disponer fe sus bienes a su antojo y de impedir la intromisión voluntaria en la definición de las reglas del intercambio -evitando que se entorpezca la fluidez del circuito fe información mercantil, y garantizando la libertad necesaria para utilizar correctamente esa información-, deberán conseguir limitar las conductas antisociales. En el despliegue de su acción, los individuos no sólo se encuentran ante la posibilidad de incorporarse, o no, al proceso de intercambio, pueden elegir tratar de lograr sus beneficios a través de medios ajenos al mercado.

El caso típico de una acción extramercantil es el robo. Un individuo puede optar por robar, antes que comerciar, y obtener así los recursos y los bienes necesarios para satisfacer sus necesidades. ¿A qué conduce una acción de esta naturaleza? Los neoliberales postulan que a través del intercambio todos los individuos saldrán beneficiados. Si alguno de ellos decide robar habrá satisfecho sus objetivos egoístas, al tiempo que impedirá la satisfacción del de los otros. Así como el intercambio es un juego de suma positiva (todos se benefician), el robo es un juego de suma cero (unos se benefician mientras que otros no). Dado que los individuos son racionales y maximizadores, adaptarán sus acciones a las nuevas reglas del juegos, es decir, todos robarán. Mientras que el proceso de intercambio genera beneficios para todos, el robo (ante la nueva actitud de los robados) congela la cuantía del botín, por lo que a la larga todos saldrán perjudicados.

Este tipo de procesos externos al mercado conduce a conductas antirracionales. Por tal motivo los individuos formularán acuerdos para evitarlos. ${ }^{11}$

10 Cfr. Buchanan, J.: Ensayos de Economía Politica.

11 Cfr. Ensayos, op.cit. 
Dado que la sociedad está constituía por individuos egoístas, racionales y maximizadores, sostiene Buchanan, y

"si estas personas pueden diferir en sus preferencias, y admitimos que algunos ámbitos de la vida son intrinsecamente colectivas y sociales, y no exclusivamente privados, el problema de la elección pública se plantea de forma inmediata ¿cómo deben conciliarse las preferencias individuales diferentes para obtener resultados que, por definición, puedan ser compartidos conjuntamente por todos los miembros de la comunidad?. ${ }^{12}$

Tres afirmaciones neoliberales, pueden ayudamos a responder esta pregunta: la primera consiste en la probabilidad de que una propuesta o candidato no pueda imponerse a los demás en una serie de enfrentamientos dos a dos. Dicha probabilidad, lleva a que, en ciertas circunstancias, la votación por mayoría simple producirá un ciclo dentro de un subconjunto de alternativas posibles ${ }^{13}$ (Paradoja del voto). La segunda se refiere a la imposibilidad de contar con una "función de bienestar social" en la que las preferencias de las personas indiquen las preferencias comunes que los individuos requieren para realizar sus elecciones normales de mercado (Teorema de Arrow). La última, supone que la incertidumbre sobre dónde estará su interés en una serie de juegos hace que una persona racional prefiera reglas que parezcan justas con independencia de la posición final que pueda ocupar. ${ }^{14}$

A partir de estos tres elementos se puede esgrimir la siguiente respuesta: dado que, debido a la paradoja del voto, se pueden producir inestabilidades e incoherencias en las preferencias que pudieran considerarse como mayoritarias, y dado que no es posible determinar una función de bienestar social, cualquier acción colectiva que pretenda ir más allá del acuerdo acerca de las reglas del juego implicará beneficiar a unos individuos en favor de otros. La única acción colectiva racional es, por tanto, la que permite determinar las reglas del juego.

\section{III.2. Marxismo analítico e individualismo metodológico}

Las implicaciones sobre la acción derivadas de la propuesta del marxismo analítico rompen con el marxismo tradicional. ${ }^{15}$

12 en Buchanan, J.: De las preferencias privadas a la filosofía pública; el desarrollo de la elección pública, p. 3.

13 Cfr. Mueller, D: Elección Pública

14 Cfr. Buchanan, J.: Imperativos Constitucionales de los 90. El orden legal para una economía libre y productiva.

15 Incluso muchos de ellos se preguntan sobre la supervivencia del marxismo después de su propia reformulación. 
Przeworski, por ejemplo, polemizando con la pro- puesta de Marx respecto del individuo, sostiene que el desafío que se le presenta al marxismo consiste en la necesidad de brindar una explicación

"de los actos individuales en unas condiciones determinadas, es decir, proporcionar unos micro fundamentos para la teoría de la historia." ${ }^{16}$

El marxismo, afirma, constituye una teoría de la historia sin una referencia específica a los individuos que la hacen. Esa postura, propone este autor, se hace imposible de sostener, dado que no se puede concebir a las acciones de los individuos como establecidas por su posición de clase:

"el desafío que se desprende del marco de la elección racional tiene un carácter específico: una teoría es satisfactoria si puede explicar la historia en función de las acciones de unos individuos racionales y orientados hacia un objetivo". ${ }^{17}$

Una preocupación similar presenta Elster en su crítica a lo que denomina "marxismo funcionalista". Elster afirma la necesidad de encontrar microfundamentos a la teoría social marxista dado que

"sin un conocimiento sólido sobre los mecanismos que operan a escala individual, las tesis marxistas de amplio alcance sobre las macroestnlcturas y los cambios de largo plazo son condenadas a permanecer como especulaciones." ${ }^{18}$

A pesar de la necesidad de introducir microfundamentos, Przeworski sostiene que el supuesto de los propietarios de recursos que maximizan beneficios en un mercado con información plena sólo representa alguna utilidad en las condiciones del capitalismo desarrollado. Esa limitada capacidad heurística lo lleva a postular que el individualismo metodológico no resulta suficiente, y que es necesario especificar supuestos adicionales para explicar la conducta individual en situaciones históricas específicas.

Dos argumentos fundamentales han realizado los "marxistas tradicionales", desde la perspectiva de Przeworski, en contra del individualismo metodológico: el primero se refiere a la formación social de las preferencias y el segundo al egoísmo.

16 en Przeworski, A.: "Marxismo y Elección Racional", p. 4. Las condiciones determinadas podrían ser consideradas como las relaciones sociales de producción, aún en ese caso, contrastaría con la propuesta de Marx, para el cual los individuos no son sino encarnaciones de dichas relaciones.

17 en Marxismo... op. cit. p. 5. Recuérdese que este marco de la elección racional es uno de los presupuestos básicos del neoliberalismo.

18 en Elster, J.: Marxismo, Funcionalismo y Teoría de los Juegos. Argumentos a favor del Individualismo Metodológico, p. 306. 
El primer argumento sostiene que la formación de la identidad individual y, por consiguiente de sus preferencias, son históricamente moldeadas por la sociedad. Este argumento le parece a Przeworski irrefutable. Sin embargo, arguye este autor, el individualismo metodológico se ubica en un momento posterior a la formulación de preferencias. ${ }^{19}$ En efecto, una vez formadas esas preferencias, por motivos que escapan a su análisis, los individuos actúan con arreglo a ellas en cada momento particular, por lo que

"la fuerza de la economía neoclásica reside en que es capaz de separar el análisis de una acción en un momento determinado de todo lo que creó las condiciones en las que se produce la acción."20

Como consecuencia de esto, afirma Przeworski, el postulado de la formación histórica de las preferencias no es contradictorio con el de la elección racional.

El segundo argumento va dirigido contra el supuesto del egoísmo en el marco de la elección racional. Este argumento, supone, según Przeworski, que el egoísmo constituye una descripción desafortunada del comportamiento individual. Respecto de este argumento, Przeworski opone tres cuestiones principales por la que sostener el presupuesto del egoísmo:

Si se deja de lado la hipótesis del egoísmo qué usar. La hipótesis contraria, de que los individuos son altruistas, es igualmente problemática. Lo que sucede en realidad es que no sabemos en qué situaciones el individuo actuará guiado por preceptos egoístas y en qué otras actuará de manera, altruista o ideológica. Por esta razón el egoísmo es fácilmente rechazable pero no reemplazable.

No hay por qué suponer que los problemas estratégicos no aparecerán en una sociedad altruista o ideológicamente guiada.

Por último, Przeworski señala que

"una descripción de la sociedad en la que coexisten individuos egoistas, altruistas e ideológicos en todo momento, podría hacer casi imposible un análisis deductivo.".

A diferencia de Przeworski, Elster asume al individualismo metodológico con menos reticencias y afirma que

19 Nosotros creemos que para el marxismo no existe tal identidad individual, por lo que resulta imposible ubicarse en un momento posterior a ella.

20 en Marxismo... op. cit. p. 6. Dentro de la economía neoclásica las preferencias son consideradas como naturales. Sobre el particular, cabrían ser resaltadas las objeciones de Douglas North respecto de la complejidad de la función de utilidad. Cfr. North, D.: Estructura y cambio en la historia económica.

21 en Marxismo... op. cit. p. 7. 
Convergencia Revista de Ciencias Sociales, núm. 8/9, 1995, Universidad Autónoma del Estado de México

"esa doctrina no es incompatible con ninguna de las propuestas verdaderas que siguen a continuación: a. los individuos frecuentemente tienen objetivos que tienen que ver con el bienestar de otros individuos; $b$. el/os frecuentemente creen en entidades supra-individuales no reductibles a creencias que tienen sobre los individuos. (..) c. muchas características de los individuos, tales como "autoridad" o "poder", son irreductiblemente de relación, de modo que una descripción exacta de un individuo debe ser hecha con referencia a otros individuos."22

Esto implica que para Elster el individualismo metodológico permite introducir consideraciones que otros individualistas rechazaran y que, sin embargo, son lógicamente pertinentes.

Los recelos de Przeworski se amplían al considerar que la consecuencia más negativa que resulta de la aplicación del marco de la acción racional es la que se opera al aplicar dicho marco en relación con la acción colectiva. El postulado genérico del individualismo metodológico sobre dicha acción

"es que las personas que comparten unos intereses y unas condiciones de vida no actuarán, en general, de forma colectiva, para promover esos intereses, aunque los resultados de la acción colectiva fueran beneficiosos para todos los obreros (por ejemplo). Ninguno de ellosparticiparía si fuera a beneficiarse de los resultados independientemente de su participación". 23

A pesar de que se han esgrimido una serie de argumentos en favor de invalidar el problema del "francotirador" con respecto a la clase obrera, ${ }^{24}$ la perspectiva del individualismo metodológico hace necesario replantear la teoría marxista de la acción de clase.

El punto de partida de Przeworski para replantear la teoría marxista consiste en recuperar con cierta singularidad el desafío neoclásico, aceptando el hecho de que la acción colectiva debe ser remitida a la racionalidad individual e incorporando la idea de que la sociedad está compuesta por individuos dentro de una "estructura social multidimencionalmente descrita". ${ }^{25}$ Sin embargo,

"Tal como se presenta ahora, el aparato técnico del individualismo metodológico, la teoría de los juegos, resulta lamentablemente insuficiente para esta tarea. Hoy en dia, lo más que puede hacer el aparato de la teoría de los juegos es dilucidar unos hechos singulares aislados que se producen en unas condiciones determinadas. No puede decir nada de la historia" 6

22 en Marxismo, Funcionalismo... op. cit. p. 306.

23 en Marxismo... op. cit. p. 8.

24 Przeworski arguye que "todos esos argumentos suponen que hay algo erróneo en una teoría que predice que los obreros en general no se organizarán como clase ni emprenderán acciones colectivas", sin embargo, lo cierto es que "típicamente los obreros no están siquiera organizados como clase". En Marxismo... op. cit. p. 8

25 La fuerza de la explicación neoclásica, está precisamente, en demostrar que la racionalidad individual esteriliza cualquier acción colectiva, excepto la definición de las reglas del juego, de allí, suponemos, lo de "cierta singularidad".

26 En Marxismo...op.cit. p 15 
Elster, en cambio, afirma que desde la teoría de los juegos y del individualismo metodológico se puede demostrar que la acción colectiva es deseable en algunos casos, aunque esta estrategia de acción en ningún caso es imperativa, sino que condicionada.

\section{III.3. La racionalidad compleja de Weber.}

Max Weber entiende por acción:

"una conducta humana (bien consista en un hacer externo o interno, ya en un omitir o permitir) siempre que el sujeto o los sujetos de la acción enlacen a ella un sentido subjetivo"27 El hecho fundamental de la acción es, pues, el sentido ${ }^{28}$ dado a ella por el sujeto, por lo que la acción social

"es una acción donde el sentido mentado por su sujeto o sujetos está referido a la conducta de otros, orientándose por ésta en su desarrollo". ${ }^{29}$

Ahora bien, no todo obrar humano es una acción. Weber introduce aquí varias distinciones. En primer lugar, el individuo puede tener una conducta reactiva, esto es, puede reaccionar sin darle un sentido mentado a esa reacción. En segundo lugar, y aún dándole sentido a su acción, puede estar orientada sólo a la reacción de los objetos materiales. En tercer lugar, no todo contacto entre los hombres es una acción con sentido dirigida a la acción de los otros. Por último, la acción íntima puede no estar dirigida a la acción de otros. Por otra parte, afirma Weber,

"la acción social no es idéntica a) ni a una acción homogénea de muchos, b) ni a la acción de alguien influido por conductas de otros. (.) Tampoco puede considerarse una «acción social» especifica el hecho de la imitación de una conducta ajena (.) cuando es puramente reactiva, y no se da una orientación con sentido de la propia acción ajena." ${ }^{30}$

Dentro de los límites de la acción con sentido, esto es, de la acción social, pueden distinguirse:

"1) racional con arreglo a fines: determinada por expectativas en el comportamiento tanto de objetos del mundo exterior como de otros hombres, y utilizando esas expectativas como «condiciones» 0 «medios» para el logro de fines propios racionalmente sopesados y 27 En Weber, M.: Economía y Sociedad, p.5

28 subjetivo de los sujetos de la acción, bien a) existe el hecho: i) en un caso históricamente dado, ii) como promedio y de un modo aproximado, en una determinada masa de caos; bien b) como construido en un tipo ideal con actores de este carácter. En modo alguno se trata de un sentido «objetivamente justo» o de un sentido «verdadero» metafísicamente fundado". En Economia.., op. cit. p. 6.

29 en Economia..., op. cit. p. 5.

30 en Economia..., op. cit. p. 19 
Convergencia Revista de Ciencias Sociales, núm. 8/9, 1995, Universidad Autónoma del Estado de México

perseguidos. 2) racional con arreglo a valores: determinada por la creencia consciente en el valor -ético, estético, religioso o de cualquiera otra forma como se la interprete-propio y absoluto de una determinada conducta, sin relación alguna con el resultado, o sea puramente en méritos de ese valor. 3) Afectiva, especialmente emotiva, determinada por afectos y estados sentimentales actuales, 4) tradicional: determinada por una costumbre arraigada." ${ }^{11}$

Además de estas distinciones, Weber afirma que una acción rigurosamente racional con arreglo a fines es una construcción típico-ideal, dado que la acción real se encuentra influida por irracionalidades de toda especie (afectos, errores).

Recordemos que para el neo liberalismo, el individuo racional (es decir, todo individuo) actúa siempre con arreglo a fines y su acción no se encuentra definida en términos de tipos, sino que, por el contrario, el individuo actúa en todo momento con arreglo al cálculo costo-beneficio. Para Weber, en cambio, la acción racional con arreglo a fines es sólo una aproximación sociológica.

Esto no implica que la sociología no pueda construir sus conceptos a partir de la clasificación de los posibles sentidos mentados "como si" la acción real transcurriera orientada conscientemente según sentido. A pesar de la reducción a tipos ideales, no se eliminan las diferencias entre la propuesta weberiana y la neo liberal. En efecto, respecto de la acción racional que, para el neo liberalismo, tiñe todos los actos humanos, tenemos los siguientes recortes: no todo acto es una acción social, no toda acción social es racional. Por otra parte,

"la acción, en especial la social y también singularmente la relación social, pueden orientarse, por el lado de sus partícipes, en la representación de la existencia de un orden legítimo".32

Esto depende de la "validez"33 de ese orden. Por otra parte, el individuo puede dirigir su acción en virtud de diversos órdenes contradictorios entre sí, incluso en una misma acción. Ello depende de la legitimidad atribuida por el individuo a los órdenes respecto de los cuales orienta su acción.

31 en Economia..., op. cit. p. 20

32 en Economia..., op. cit. p. 25.

33 “«Validez» de un orden significa para nosotros algo más que una regularidad en el desarrollo de la acción social simplemente determinada por la costumbre o por una situación de intereses (..) $\mathrm{Al}$ «contenido de sentido» de una relación social le llamamos a) «orden» cuando la acción se orienta (por término medio o aproximadamente) por «máximas» quepueden ser señaladas. Y sólo hablaremos, b) de una «validez» de este orden cuando la orientación de hecho por aquellas máximas tiene lugar porque en algún grado significativo (es decir, en un grado que pese prácticamente) aparecen válidas para la acción, es decir, como obligatorias o como modelos de conducta”. 
Toda vez que han sido definidas las posibles orientaciones de la acción, se impone elucidar el concepto "racional". $\mathrm{N}$ o son pocas las diferencias que embargan a los analistas de Weber respecto del contenido definitivo de ese concepto.

Algunos autores, sostienen que la razón de estas divergencias respecto de la racionalidad se funda en el hecho de que no existe un único concepto que la definía a lo largo de la obra de Weber. Basándose en los últimos escritos de este autor -fundamentalmente en la Sociología de la Religión-, Gil Villegas distingue cuatro tipos de racionalidad: la conceptual, la instrumental, la sustancial y la formal; las cuales operan sobre tres esferas: la religión, la economía y el derecho.

La racionalidad conceptual ordena y da sentido a la realidad por medio de ideas y no persigue controlarla a partir de la acción. La racionalidad instrumental supone la consecución metódica de un fin determina- do, práctico, por medio de un cálculo preciso de los instrumentos adecuados para ello. La racionalidad formal es el tipo inconfundible del occidente moderno y capitalista, y se relaciona con las esferas de la vida y la estructura de dominación que forjó sus límites precisos con el proceso de industrialización. Consiste en el cálculo puro basado en reglas abstractas. Las decisiones se toman respecto de esas reglas y no en relación a personas concretas. El vínculo entre la racionalidad instrumental y la formal constituyen el proceso de racionalización específica del occidente industrial.

Un último tipo es la racionalidad sustantiva. Según Gil Villegas

"este tipo ordena directamente la acción en patrones, no sobre la base del mero esquema de medios a fines para solucionar los problemas rutinarios, sino que se basa en postulados de valor pasados, presentes o potenciales. Un postulado valorativo implica conjuntos enteros de valores que varian en omnicomprehensividad, contenido y consistencia interna. Asi este tipo de racionalidad existe como manifestación de la capacidad inherente del hombre para la acción valorativa" ${ }^{34}$

Luis Aguilar Villanueva, en cambio, afirma que la "racionalidad occidental" es un concepto

"construido selectivamente a partir del capitalismo industrial y del estado constitucional, el concepto de racionalidad pretende haber capturado lo propio y original de la sociedad occidental moderna." ${ }^{35}$

A nuestro entender, Aguilar Villanueva cae en el error, definido por Gil Villegas, de

34 en El concepto de racionalidad en la obra de Max Weber, p. $42-43$.

35 en Aguilar Villanueva, L.: En torno del concepto de racionalidad en Max Weber, p. 81. 
Convergencia Revista de Ciencias Sociales, núm. 8/9, 1995, Universidad Autónoma del Estado de México

"incorporar todos los sentidos de racionalidad weberiana en este criterio y atribuirle una superioridad frente a otros tipos de racionalidad. Weber afirmará que este tipo es mejor que otros para la aparición del capitalismo moderno, pero esto no implica que le hay a atribuido una superioridad inmanente con relación a otros aspectos vitales", ${ }^{36}$

antes bien,

"esta determinación no presupone ningún elogio al tipo particular de racionalismo que se ha reconocido. Por el contrario, sus caracteristicas pueden ser evaluadas en términos altamente negativos y es muy difícil encontrar en los escritos de Weber una visión optimista acerca de la racionalidad tipica del Occidente moderno."37

Para Aguilar Villanueva, en cambio,

"el concepto histórico de racionalidad quiere denotar el actuar especifico de una especifica sociedad cuyos principios de organización han hecho posible calcular la realización de los fines, al haber logrado transformar todo lo natural y socialmente existente en medios para el actuar, por ende, en realidades utilizables y controlables en sus desempeños. ${ }^{\text {"38 }}$

Es evidente que Aguilar Villanueva quiere vincular el concepto de racionalidad de Weber con el del neo- liberalismo, intento que se desvanece si incorporamos, fundamentalmente, el concepto de racionalidad sustancial, ya que, como señala Gil Villegas,

"Puesto quelosvalorespueden ser en principio infinitos, la acción puedeordenarse en patrones o enteros modos de vida en un número infinito deformas. (.) La infinidad y pluralidad de posibilidades valorativas sitúa la racionalidad sustantiva en un perspectivismo radical. Para Weber, la racionalidad sustantiva y los procesos de racionalización basados en el/a, siempre han existido en referencia a direcciones o «puntos de vista» últimos, según lo nota en la «Introducción» a su Sociologia de la religión. Este tipo de racionalizaciones depende asi de la preferencia implicita o explícita, consciente o inconsciente, por ciertos valores últimos y por la sistematización de la acción para conformarse a esos valores. Estos valores adquieren «racionalidad» debido meramente a su status como postulados valorativos. (.) La discusión sobre la relatividad de la racionalidad queda asi conectada con otro de los últimos textos de Weber (el de La ciencia como vocación), donde se describe el pluralismo axiológico y la eterna luch a existente entre los distintos valores. Las diversas esferas vitales o institucionales defienden sus propiospostulados valorativos como «racionales» y condenan a los que se le oponen como «irracionales». ". ${ }^{39}$

En un sentido similar Jürgen Habermas afirma que

"en un primer paso Weber considera, pues, la racionalidad sólo bajo el aspecto de utilización delosmedios. Pero después diferencia este concepto distinguiendo en las acciones enderezadas a un fin dos aspectos susceptibles de racionalización: no sólo los medios y los modos de

36 en El concepto de racionalidad... op. cit. p. 43.

37 en El concepto de racionalidad... op. cit. p. 39.

38 en torno del concepto de... op. cit. p. 82-83-84.

39 en El concepto de racionalidad... op. cit. p. 43 .. 
utilizarlos pueden ser más o menos racionales, esto es, eficaces en relación con un fin dado; también los fines mismos pueden ser más o menos racionales, es decir, estar objetivamente mejor o peor elegidos, supuestos unos determinados valores, unos determinados medios y unas determinadas condiciones de contorno. Entre las condiciones de la acción racional con arreglo a fines no solamente figura la racionalidad instrumental de los medios, que el actor supone subjetivamente o que puede ser comprobada empiricamente, sino también la racionalidad en la elección de un fin seleccionado con arreglo a valores"."

Y abre así la posibilidad de considerar otra distinción weberiana fundamental: la que se produce entre racionalidad formal y material. Cabe destacar aquí que si reducimos toda la racionalidad del occidente industrial, como lo hacen aquellos que quieren encontrar en Weber el fundamento del neoliberalismo, a la interacción entre la racionalidad formal e instrumental, la distinción que propone Weber entre racionalidad formal y material no resulta posible.

La racionalidad formal se refiere a la técnica, es una racionalidad con arreglo a fines. Mientras que la racionalidad material es una racionalidad con arreglo a valores, en la que intervienen las exigencias éticas, políticas, utilitarias, estamentales, igualitarias, etc. Siendo los puntos de vista valorativos ilimitados.

\section{LAS TEORIAS INTERMEDIAS}

No podemos definir de manera clara el concepto de "teorías intermedias". Antes bien, es una categoría residual que contiene a teorías heterodoxas.

En este apartado hemos decidido incorporar, a modo de ejemplo, tres propuestas: la de Keynes, la de Hirschman y la de North.

Las dos primeras parten del concepto de individuo y ponen en cuestión el carácter racional de sus decisiones, la segunda, además, concibe la posibilidad de la acción colectiva, incluso como imperativa, dada determinadas circunstancias. Por último, Douglas North, desde una posición liberal, cuestiona acerca de los límites del individualismo metodológico.

\section{IV.1. La acción no tan racional en Keynes y Hirschman}

Keynes reconoce en el empresario un comportamiento racional, dado que ajusta sus costos de producción con el fin de obtener el máximo beneficio. Para ello,

40 en Habermas, J.: Teoría de la acción comunicativa, Tomo 1, Racionalidad de la acción y racionalización social, p. 230-231. 
"el empresario (incluyendo en este término tanto al productor como al inversionista) tiene que hacer las mejores previsiones que estén a su alcance sobre lo que los consumidores podrán pagarle cuando esté listo para abastecerlos". ${ }^{41}$

Estas expectativas son de dos clases: las primeras de ellas se refieren al precio que el empresario puede obtener por su producción, una vez realiza$\mathrm{da}$, en el momento en que se inicia la producción; las segundas, a lo que el empresario puede ganar, en el futuro, en el caso que se compre la producción terminada. A las primeras las llamará expectativas de corto plazo y, a las otras, expectativas de largo plazo.

En el caso de las expectativas de corto plazo, el empresario posee un grado bastante elevado de control; mas sobre las de largo plazo el panorama es más sombrío. Esto se debe al hecho de que la demanda efectiva constituye, para el empresario, una hipótesis. Por lo que el empresario intentará construir su estimación en base a la información originada en situaciones pretéritas similares.

Este tipo de acción no puede considerarse irracional, dado que el empresario despliega su actividad de acuerdo con expectativas racionales de obtener el máximo beneficio, sin embargo, afirma Keynes, ahora en términos generales,

"estamos simplemente acordándonos de que las decisiones humanas que afectan el futuro, ya sea personales, politicas o económicas, no pueden depender de la expectativa matemática estricta, desde el momento que las bases para realizar semejante cálculo no existen; y que es nuestra inclinación natural a la actividad la que hace girar las ruedas escogiendo nuestro ser racional entre las diversa alternativas lo mejor que puede, calculando cuando hay oportunidad; pero con frecuencia hallando el motivo en el capricho, el sentimentalismo o el azar". 42

Por tanto, a pesar de sus objetivos de maximización, la distancia que media entre la persecución del fin y los logros obtenidos, hace que el proceso general de la acción, tomando en cuenta la información efectiva que se produjo luego de la decisión, puede no haber sido del todo racional debido al error, o pudo incluso ser caprichosa, sentimental o azarosa.

Por su parte, Hirschman sostiene que

"los actos de consumo, al igual que los actos de participación en los asuntos públicos, que se realizan porque se espera obtener así una satisfacción, también generan decepción e insatisfacción”.43

41 en Keynes, J.: Teoría general de la ocupación. el interés y el empleo, p. 50.

42 en Teoría general... op. cit. p. 148.

43 en Hirschman, A.: Interés privado y acción pública, p. 18. 
En esta afirmación inicial deja sentada las bases de las discrepancias y los acuerdos: en primer lugar, se aleja de la figura del actor racional del neo liberalismo, esto por dos razones: primero, porque la acción emprendida por el individuo lejos está de garantizar la maximización de los beneficios (Keynes), y, segundo, porque aún si lograra maximizarla

"los hombres creen que desean una cosa y cuando la obtienen descubren con desaliento que no la desean tanto como creían o la desean en absoluto, y que en realidad desean otra cosa, cuya existencia casi ni sospechaban". ${ }^{44}$

En segundo lugar, toda acción, afirma Hirschman, se encuentra precedida por la formulación de un proyecto:

"una parte de este proyecto son ciertas imágenes mentales, o expectativas, acerca de su naturaleza y acerca de la clase y el grado de satisfacción que brindará la actividad. La existencia independiente del proyecto con sus expectativas implica que puede diferir considerablemente de la realidad experimentada cuando el proyecto se ejecute, es decir, cuando efectivamente se realice el consumo. De aquí deriva la posibilidad de la decepción, o quizá de su opuesto". 45

Así, la propuesta de Hirschman acuerda con la de Keynes en que las acciones se encuentran guiadas por formulaciones hipotéticas de los resultados a obtener, y, por lo tanto, en el momento de la realización de la acción pueden existir discrepancias entre las expectativas que guiaron la acción (decisión) y el resultado (satisfacción).

Toda vez que se ha incorporado el concepto de decepción, podemos pasar a explicar el ciclo privado- público-privado. A grandes rasgos, este ciclo consiste en el paso sucesivo de formas de acción privadas (individuales) a formas de acción pública (colectivas), y de ésta a la primera, motivado por decepciones que se originan en cada uno de esos espacios de acción. Todo consumidor, afirma Hirschman,

"dispone de dos tipos principales de reacciones activas ante el descontento. Uno es la salida, la única respuesta a la que han prestado atención los economistas y la única que consideran eficaz. Esta es precisamente la reacción del consumidor que confrontado con una experiencia decepcionante en relación con un proveedor, busca una fuente de abastecimiento diferente, en un ambiente competitivo. (..) Pero los consumidores decepcionados tienen otra opción que ha pasado por alto el análisis económico: puede alzar su voz y participar asi en diversas acciones que van desde la queja estrictamente privada (pidiendo una devolución) basta la acción pública en aras del interés general".46

44 en Interés... op. cit. p. 29. Nótese que este puede ser el resultado de una acción motivada en el sentimentalismo, el azar o el capricho como la que señala Keynes

45 en Interés... op. cit. p. 20.

46 en Interés... op. cit. p. 74 
Convergencia Revista de Ciencias Sociales, núm. 8/9, 1995, Universidad Autónoma del Estado de México

\section{En términos generales,}

"las reacciones de la voz derivadas de las experiencias de consumo decepcionantes reforzarán la reacción de la salida, y la probabilidad de un viraje hacia la acción pública aumentará consiguientemente". 47

Un elemento adicional a considerar consiste en el hecho de que el paso de la acción individual a la colectiva no se sucede inmediatamente después de una decepción.

Toda vez que el individuo se ha frustrado por los desencantos de la vida privada se abre la etapa de su acción pública. En esta etapa el individuo, sostiene Hirschman, desafía el problema olsoniano del gorrón, ${ }^{48}$ e intenta satisfacer sus deseos a través de la acción pública. Sin embargo, la vida pública tiene sus propias decepciones:

"las actividades públicas fracasan a causa de sus ambiciones expansionistas intrinsecas. Por tratar de ocupar en las vidas individuales un lugar excesivo en relación con lo que puede tolerarse a largo plazo, tales actividades se reducen drásticamente, y el «ciudadano público» castigado vuelve a sus asuntos privados. (..) Otra gran corriente de decepción con la vida pública se origina en una situación muy diferente, casi opuesta: bajo las condiciones modernas, los ciudadanos están sujetos a límites estrictos en lo tocante a su participación en los asuntos públicos, ya que ciertas instituciones politicas les impiden expresar con toda intensidad sus sentimientos a este respecto". ${ }^{49}$

47 en Interés... op. cit. p. 75.

48 "Mancur Olson presentó a mediados de los años sesenta una formulación vigorosa e influyente de esta cuestión en su libro The logic of Collective Action. Allí demostraba Olson la improbabilidad de que los ciudadanos individuales participen en la acción colectiva aunque los beneficios del resultado probable de esa acción para el individuo pudiera superar a los costos de la participación. La razón es el famoso fenómeno del «viaje gratis»: dado que el resultado de la acción colectiva (si la suponemos eficaz) es un bien público que pueden disfrutar todos independientemente de la participación previa, el individuo se ve tentado a negar su aportación con la esperanza de que otros se sacrifiquen por él. En consecuencia, todos esperan que otro actúe primero, y no ocurre nada" (en Interés... op. cit. p. 88-89). Sin embargo, "hay una gran realización asociada a los esfuerzos del ciudadano por la felicidad pública. En efecto, estos esfuerzos se comparan a menudo con las experiencias agradables de comer y beber: decimos que los ciudadanos «tienen hambre y sed de justicia», y Tocqueville se refirió al "ansia de la libertad" que ha desarrollado perdurablemente «un puñado de nosotros». Es en la lucha misma por la justicia y la libertad que se sacian la sed y el ansia ¿Quién querrá entonces perderse todo es placer activo y obtener un viaje gratis a lo que es a lo sumo el resultado cómodo, y a menudo decepcionante, de esos procesos? En estas circunstancias, la elección de un viaje gratuito equivaldría a declinar una comida deliciosa y tragarse en su lugar una pastilla productora de saciedad que ni siquiera es particularmente efectiva" (en Interés... op. cit. p.102).

49 en Interés... op. cit. p. 115. 
Estas decepciones, también en forma acumulativa, conducen al individuo a la vida privada, cerrando así el ciclo.

\section{IV.4. Individuos e instituciones: la heterodoxa visión de North}

Douglas North sostiene que la acción racional maximizadora de los beneficios, tal como la presenta el neo liberalismo, supone un mundo sin fricciones en el que no existen costos de información, incertidumbre y costes de transacción.

Por otra parte, una acción de esa naturaleza no puede desplegarse, según North, sin una estructura de incentivos, para lo cual se requiere del establecimiento de derechos de propiedad perfectamente definidos que no pueden hacerse respetar sin costos.

De acuerdo con North, la satisfacción de los fines perseguidos por el individuo a través de la acción no logra explicarse si no se apela a la" estructura de la organización política y económica de la sociedad, dado que son éstas las que determinan las formas de cooperación y competencia, al tiempo que especifican las formas por las que hacer respetar las reglas necesarias para tales cooperación y competencia.

En el marco de estas reglas, los que despliegan un papel primordial son los derechos de propiedad. Dado que el Estado es el encargado de especificarlos, éste determina, en buena medida, la naturaleza de la acción de los individuos. Aspecto éste, totalmente olvidado por los teóricos liberales.

Esto genera, según North, uno de los problemas centrales de la explicación neo liberal. Los individuos aceptan las reglas establecidas, aún cuando la persecución racional de sus fines debiera obligarlos a violarlas. Para superar este problema, la explicación neo liberal combina, por un lado, el concepto de maximización de la riqueza, y, por el otro, el modelo de Estado hobbesiano que limita la conducta, 10 cual la lleva a una contradicción evidente.

De este modo, afirma North, la verdadera consecuencia de este tipo de comportamientos es que los individuos no siempre actúan movidos por motivos maximizadores, muchas veces actúan inspirados en el deber y, en términos generales, inspirados en principios ideológicos.

Una última objeción supone que, a pesar del problema del Gorrón, los individuos suelen actuar en forma colectiva.

Sintetizando, para North, la formulación del concepto de la acción racional maximizadora de los beneficios de la teoría liberal permite explicar una gran parte de los comportamientos individuales, pero no todos. Aquellos que no puede explicar se deben en buena medida a seis factores principales: 
Los costos de información, incertidumbre y transacción pueden imposibilitar, u obstaculizar el cálculo racional.

Los costos que implican la especificación y cumplimiento de los derechos de propiedad, hace que no siempre éstos puedan ser definidos con claridad o impiden el cuidado de su cumplimiento. De este modo, los incentivos para la acción racional maximizadora, inspirados en esos derechos, muchas veces suelen ser difusos, generando así una fuente de incertidumbre adicional al cálculo racional.

Los liberales tienden a ver en el mercado la única institución que determina el comportamiento racional, sin embargo, descuidan la influencia que el Estado ejerce a través de la definición y cuidado de su cumplimiento.

Las reglas establecidas por el Estado limitan el despliegue de la búsqueda constante de los beneficios, y, a pesar de ello, los individuos tienden a respetar esos límites, contrariando así el supuesto de que el cálculo racional guía todas las acciones individuales.

La acción colectiva no es imposible. Prueba de ello' son las manifestaciones históricas en la que los individuos, en forma colectiva, pugnan por modificar los derechos de propiedad.

Las razones esgrimidas en los dos puntos anteriores hacen pensar que la ideología es una fuente de motivaciones similar a la búsqueda de los beneficios.

\section{CONCLUSIONES}

La primera conclusión que podemos aportar, obvia por cierto, es que la descripción de las diversas posturas analizadas nos devuelve al punto de partida mismo: la situación nos remite pues a la existencia múltiples paradigmas que en un sentido kuhniano hablan en idiomas diferentes. Sin embargo, esto no quiere decir que nos veamos obligados a embanderamos detrás de las distintas posturas, aunque no debemos olvidamos que las implicaciones de las distintas teorías de la acción no sólo nos remiten a problemas teóricos sino, fundamentalmente, a diferencias políticas.

Lo que nadie puede negar es que en el marco definido por sus propios supuestos cada teoría es lógicamente sólida. Precisamente allí se encuentra buena parte de la dificultad. Así, el marxismo impugnará al individualismo metodológico desde el supuesto de que todas las características individuales son necesariamente de relación y que por lo tanto no se puede explicar a los individuos como si fueran efectivamente agentes aislados. En cambio, el individualismo metodológico sostendrá que si todas las características individuales 
fueran necesariamente de relación todos los actos humanos, desde el paseo dominical hasta el gusto por el licor, estarían determinadas por las estructuras sociales.

Es evidente que la capacidad heurística de cual- quiera de estas teorías, tomadas de manera radical, se reduce considerablemente. La respuesta, creemos, debe provenir de un nuevo esfuerzo teórico por superar los estancamientos y comenzar a recorrer nuevos derroteros referidos a sujetos y acciones concretas, con un alto contenido empírico.

No es este el lugar para la toma de posiciones. Quedará esto para otro lugar. Sin embargo, nos resulta indispensable expresar una sospecha inicial: la revisión de las distintas propuestas nos lleva a pensar que algunos autores construyen entre los individuos enormes paredes, mientras que otros tienden, con el mismo ímpetu, a construir entre ellos puentes. Las paredes, mientras sean analíticas, pueden sernos de gran utilidad, tanto como los puentes, siempre que éstos no sean demagógicos.

\section{BIBLIOGRAFIA}

Aguilar Villanueva, Luis F.: "En tomo del concepto de racionalidad en Max Weber”, en Olivé, León (Comp.): Racionalidad, Siglo XXI-UNAM, México, 1988.

Buchanan, James: De las preferencias privadas a la filosofía pública; el desarrollo de la elección pública, Pro-desarrollo, Nro. 12, Lima, Marzo de 1989. Buchanan, James: "Imperativos Constitucionales de los 90. El orden legal para una economía libre y productiva”, en Autores Varios: Vertientes de la Modernización, Perspectivas de la Modernización Politica, JEPES, México, 1990.

Buchanan, James: Ensayos de Economía Politica, Alianza Editorial Mexicana, México, 1990.

Elster, Jon: "Marxismo, Funcionalismo y Teoría de los Juegos. Argumentos a favor del Individualismo Metodológico", en Torres Rivas, Edelberto (Comp.): Politica. Teoría y Métodos, Editorial Universitaria Centroamericana, San José, 1990.

Elster, Jon: Making sense of Marx, Cambridge University Press y Editions de la Maison des Sciences de I'Homme, Londres, 1985.

Gil Villegas, Francisco: "El concepto de racionalidad en la obra de Max Weber”, Revista Mexicana de Ciencias Politicas y Sociales, Nro. 117-118, México, jul-dic. 1984. 
Habermas, Jürgen: Teoría de la acción comunicativa, Tomo 1, Racionalidad de la acción y racionalización social, Taurus, Madrid, 1986.

Hayek, F .A.: La fatal arrogancia: los errores del socialismo, Centro de Estudios en Economía y Educación, A.C., México, 1990.

Hirschman, Albert O.: Interés privado y acción pública, Fondo de Cultura Económica, México, 1986.

Keynes, John M.: Teoría general de la ocupación, el interés y el empleo, Fondo de Cultura Económica, México, 1986.

Marx, Carlos y Federico Engels: La ideología alemana, Pueblos Unidos, Montevideo, 1968.

Marx, Karl: El capital, Siglo XXI, México, 1990.

Marx, Karl: La miseria de la filosofía, Siglo XXI, México, 1987.

Mueller, Denis: Elección Pública, Alianza Editorial, Madrid, 1984.

North, Douglas C.: Estructura y cambio en la historia económica, Alianza Editorial, Madrid, 1984.

Przeworski, Adam: "Marxismo y Elección Racional", Revista Doxa, Buenos Aires.

Weber, Max: Economia y sociedad, Fondo de Cultura Económica, México, 1987. 